\title{
Length-weight relationships of 20 fish species from Pahang River, Maran district, Pahang, Malaysia
}

\begin{abstract}
This study reports the lengthï weight relationships (LWR) of 20 fish species from the Pahang River, Maran district, Pahang, Malaysia. The river supplies fishes mainly for local consumption and is a principal body of water for freshwater aquaculture in Malaysia. A total of 12 LWR of fishes were unknown to FishBase, and five new maximum lengths of fishes were identified from the study.
\end{abstract}

Keyword: Length-weight relationships; 20 fish species; Pahang River 